\title{
Age-Related Changes in the Fertility of Hippelates pusio, H. bishoppi, and H. pallipes (Diptera: Chloropidae) ${ }^{1}$
}

\author{
M. G. KARANDINOS ${ }^{2}$ AND R. C. AXTELL \\ Department of Entomology, North Carolina State University, Raleigh 27607
}

\section{ABSTRACT} egg hatchability) of Hippelates pusio Loew, H. bishoppi Sabrosky, and $H$. pallipes (Loew) adults were determined in laboratory experiments. The hatchability of $H$. pusio eggs at $27^{\circ} \mathrm{C}$ was not affected by parental age, that of $H$. bishoppi decreased linearly only with maternal age, and that of $H$. pallipes seemed to decline with the age of both parents. Egg hatchability of all 3 species declined rapidly when females were deprived of males. The decline was more rapid in $H$. bishoppi and $H$. pallipes than in $H$. pusio. At least one copulation for each gonotrophic cycle was required for females to maintain suffi-
The age-related changes in the fertility (measured by

cient viable sperm to fertilize all of their viable eggs. Males of the 3 species, at $27^{\circ} \mathrm{C}$, produced viable sperm throughout their lives,

At $33^{\circ} \mathrm{C}$, the adults of $H$. pallipes deposited eggs with much lower hatchability than at $27^{\circ} \mathrm{C}$. The difference in hatchability of $H$. pusio eggs was less extreme but was significantly lower at $33^{\circ} \mathrm{C}$ than at $27^{\circ} \mathrm{C}$. At $33^{\circ} \mathrm{C}$, $H$. bishoppi deposited eggs at the beginning of their lives with no significant difference in hatchability from those at $27^{\circ} \mathrm{C}$. However, over the entire life span the decline in hatchability at $33^{\circ} \mathrm{C}$ was slightly greater than at $27^{\circ} \mathrm{C}$.

The fertility and fecundity of many insect species are affected by various factors including parental age and density. The effects of adult density on fecundity and fertility of Hippelates pusio Loew have been found insignificant. (Karandinos and Axtell 1972). The purpose of the present study was to determine the age-related changes in the fertility of $H$. pusio, H. bishoppi Sabrosky, and H. pallipes (Loew). The hatchability of the eggs was used as a measure of the age-specific parental fertility. Any observable change in the magnitude of the fertility during the life span was assumed to be a reflection of the aging process, since aging is defined as changes in living systems resulting from the passage of time (Strehler 1962). These changes are reflected in the various biological performances of the individual, including mating behavior, fecundity, fertility, and characteristics of the offspring.

Investigations of fecundity in Drosophila (Shapiro 1932, McMillan et al. $1970 \mathrm{a}, \mathrm{b}$ ) and Habrobracon (Grosch 1968) have revealed a decline in the number of eggs laid with increasing age. This senile decline occurs in Hippelates beginning after the 1st gonotrophic cycle. ${ }^{3}$

Fertility also declines with increasing age. Ludwig and Fiore (1960) reported that the hatchability of yellow mealworm, Tenebrio molitor L., eggs decreased from $90 \%$ during the 1st 2 months to $50 \%$ 4 months after emergence. Raros and Chiang (1969) found that maternal age of the European corn borer, Ostrinia nubilalis (Hübner), had no effect on egg fertility, but the failure of fully developed embryos to hatch increased with the female's age. Johansson (1958) found that the reproductive organs of old females of Oncopeltus fasciatus (Dal-

\footnotetext{
${ }^{1}$ Research supported in part by PHS Training Grant ES00069 from the National Institutes of Environmental Health Sciences from the National Institutes of Environmental Health Sciences Paper no. 3692 of the Journal Series of the North Carolina State University Agricultural Experiment Station. Received for publi-
cation Mar. 23, 1972. cation Mar. 23, 1972.

Wiscesent address: Department of Entomology, University of Wisconsin, Madison 53705

M. G. Karandinos. 1971. Analysis of density and aging effects on the reproduction of Hippelates eye gnats (Diptera:
Chloropidae). Ph.D. thesis, N. C. State University, Raleigh. 135 p.
}

las) were reduced in size with abnormal growth, and fused ovarioles sometimes occurred. The presence of fewer micropyles in eggs produced by older females of Rhodnius prolixus Stål may account for a lower rate of hatching (Beament 1947).

In Drosophilia melanogaster Meigen, the total number of ovarioles and the number of atrophied ones are constant with increasing age of the females, but the proportion of blocked ovarioles increases at the expense of the functional ones (Wattiaux 1967). Somewhat similar situations were found by Smith (1964) in the grasshoppers Melanoplus sanguinipes (F.) and Camnula pellucida (Scudder) in which the number of ovarioles remained nearly constant throughout the adult's life, but in some of the older females only a third of the ovarioles were producing full-sized eggs. Smith (1964), speculated that resorption of eggs may have occurred, possibly as a result of inadequate nutrition. In Habrobracon, declining egg fertility with increasing age of the mother has been studied in depth (Grosch 1968). The egg death occurs predominantly in stage 3 , indicating that the embryo was able to accomplish cleavage and form the blastoderm but lacked either the information or the materials to proceed in development. Cell division and differentiation apparently proceed at a faster rate in the ovarioles than the somatic tissues can manufacture and transfer materials to the ovary.

\section{MATERIALS AND METHODS}

The flies used in our experiments were obtained from laboratory colonies of $H$. pusio, H. bishoppi, and $H$. pallipes, maintained at $27^{\circ} \mathrm{C}, 55 \% \mathrm{RH}$, and continuous illumination. The experimental flies were confined in cylindrical plastic containers $(3.6 \mathrm{~cm}$ height $\times 5.2 \mathrm{~cm}$ diam). Ventilation was insured by 2 side openings covered with 100 -mesh screen. Water was provided by a wet piece of cellucotton resting on a screened opening of the lid. The food consisted of dried beef blood, honey, strained prunes, and yeast. Only flies which had emerged during the previous $24 \mathrm{hr}$ were used in the experiments. 
The initial number of pairs confined in each container (replicate) was 50 for $H$. pusio, 75 for $H$. bishoppi, and 60 for $H$. pallipes. Four replications were used per "treatment." In the 1st and 2nd treatments, the individuals of only one sex were left to age, while the individuals of the opposite sex were replaced by young virgin ones at various time intervals. Thus in these 2 treatments any change in the hatchability of eggs is assumed to reflect the aging effects of the nonreplaced sex or some kind of interaction. In a $3 \mathrm{rd}$ treatment, both sexes were left to age, and the hatchability of their eggs was determined in regular time intervals throughout the parental lives. Experiments were conducted at $27^{\circ} \mathrm{C}$, $55 \% \mathrm{RH}$, and continuous illumination of $300 \mathrm{ft}-\mathrm{c}$. Previous coincidental observations had indicated that the hatchability of eggs deposited at $33^{\circ} \mathrm{C}$ was extremely low, particularly for $H$. pallipes. Therefore, a 4th treatment was included in which both parents were left to age at $33^{\circ} \mathrm{C}$, the other conditions being the same.

At nearly equal time intervals (1-3 days) a large sample of eggs (at least 150 when available) was taken from each container for determination of their hatchability. At the same time the flies were transferred to clean containers. The eggs were incubated at $30^{\circ} \mathrm{C}$ for 6 days on moist blotting paper. This procedure of incubation results in hatching of all viable eggs (Karandinos and Axtell 1967a). In treatments where the females aged while the males were young, the male individuals were removed at intervals of ca. 6 days and replaced with 1 - to 2 day-old virgin males. The number of young individuals used in each replacement was equal to the number of surviving females. The same procedure was followed for treatments where the males aged while the females were young, i.e., the females were replaced. The number of replacements for the nonaging sex were 5 for $H$. pusio, 5 for $H$. bishoppi, and 4 for $H$. pallipes, which has a shorter life span.

Because a large egg sample was desired for estimation of egg hatchability, dead flies of the aging sex were occasionally replaced by live ones of the same age kept in a separate reserve colony under the same environmental conditions. This replacement of dead individuals was practiced also in the treatments where both sexes aged. Thus, the sex ratio was maintained at $1: 1$ and the size of the cohorts remained relatively large.

The hatchability of eggs after females were deprived of males was also determined. The female flies removed from the treatment involving young females and aging males were placed in separate containers without males. The hatchability of their eggs was determined at various subsequent times until no viable eggs were deposited.

\section{RESULTS}

As shown in Fig. 1, the fertility of females and males of $H$. pusio remained constant with age up to ca. 50 days at $27^{\circ} \mathrm{C}$. At $33^{\circ} \mathrm{C}$ the hatchability of eggs when both sexes aged was significantly lower
(5\% level) than at $27^{\circ} \mathrm{C}$ and declined steadily beyond the parental age of ca. 24 days. The life span was shortened at $33^{\circ} \mathrm{C}$.

The hatchability of $H$. bishoppi eggs (Fig. 2) declined steadily and linearly with time when either the females or both sexes were aging. The hatchability declined at the same rate in both treatments. Eggs produced by young females and aging males of $H$. bishoppi had a constant hatchability. When both parents were aging at $33^{\circ} \mathrm{C}$, their life span was shorter and the hatchability of their eggs declined slightly faster than at $27^{\circ} \mathrm{C}$.

The hatchability of $H$. pallipes eggs declined with the age of either or both parents at $27^{\circ} \mathrm{C}$ (Fig. 3). The hatchability at $33^{\circ} \mathrm{C}$ was extremely low with the exception of the eggs collected on day 3. This exception is probably a result of the fact that eggs deposited up to day 3 had reached an advanced stage of oögenesis and the females had been inseminated while kept at the rearing room temperature $\left(27^{\circ} \mathrm{C}\right)$ prior to initiation of the experiment. The $33^{\circ} \mathrm{C}$ exposure of the females during oviposition and of newly deposited eggs did not halt the normal development of the embryo. This explanation is consistent with our previous findings ${ }^{4}$ that incubation of $H$. pallipes eggs at $35^{\circ} \mathrm{C}$ did not reduce their hatchability. Thus the low hatchability of eggs beyond day 3 of this experiment resulted from the preovipositional effect of $33^{\circ} \mathrm{C}$ on the viability of gametes and/or the mating behavior. It is not known which sex or stages of gametogenesis were affected.

In treatments where males aged while females were kept young (by replacements) the various groups of the removed females were isolated without males and the hatchabilities of their eggs deposited at various subsequent time intervals were determined. These females were assumed to have mated before removal. As shown in Table 1, egg hatchability steadily declined after the females were deprived of males. Because these females were only $6-7$ days old at the time of male deprivation, an examination of the data in Table 1 and Fig. 1, 2, and 3 indicates that the decline in egg hatchability was due to sperm depletion rather than to aging of females. Apparently, Hippelates require frequent mating to lay fertilized eggs.

The data in Table 1 were computed from egg samples rather than the total number of deposited eggs. Such numbers could be used to obtain an index of the amount of sperm utilized in various time intervals after male deprivation. To obtain such numbers, the percents in Table 1 were converted to the numbers of hatchable eggs deposited in each age interval (utilizing data on age-specific fecundities) $)^{3}$ and the obtained numbers were expressed as percents of the total number of hatchable eggs deposited throughout the life span. Assuming that the viability of sperm does not change with

${ }_{4}^{4}$ M. G. Karandinos. 1966. Comparative effects of temperature on Hippelates pusio, H. bishoppi and H. pallipes (Diptera: Chloropidae). M.S. thesis, N. C. State Vniversitv. Raleigh. 117 p. 
time, the trend of these percents with time corresponds to the trend of the amount of sperm utilized at each time interval following male deprivation. The hypothesis was made that this amount,

$$
\frac{d y(t)}{d t}
$$

was proportional to the amount, $y(t)$, of sperm present in the spermathecae at time $t$, and therefore,

$$
\frac{\mathrm{dy}(\mathrm{t})}{\mathrm{dt}}=-\mathrm{ky}(\mathrm{t})
$$

where $\mathrm{k} \geqslant 0$, is a proportionality constant.

H. pusio

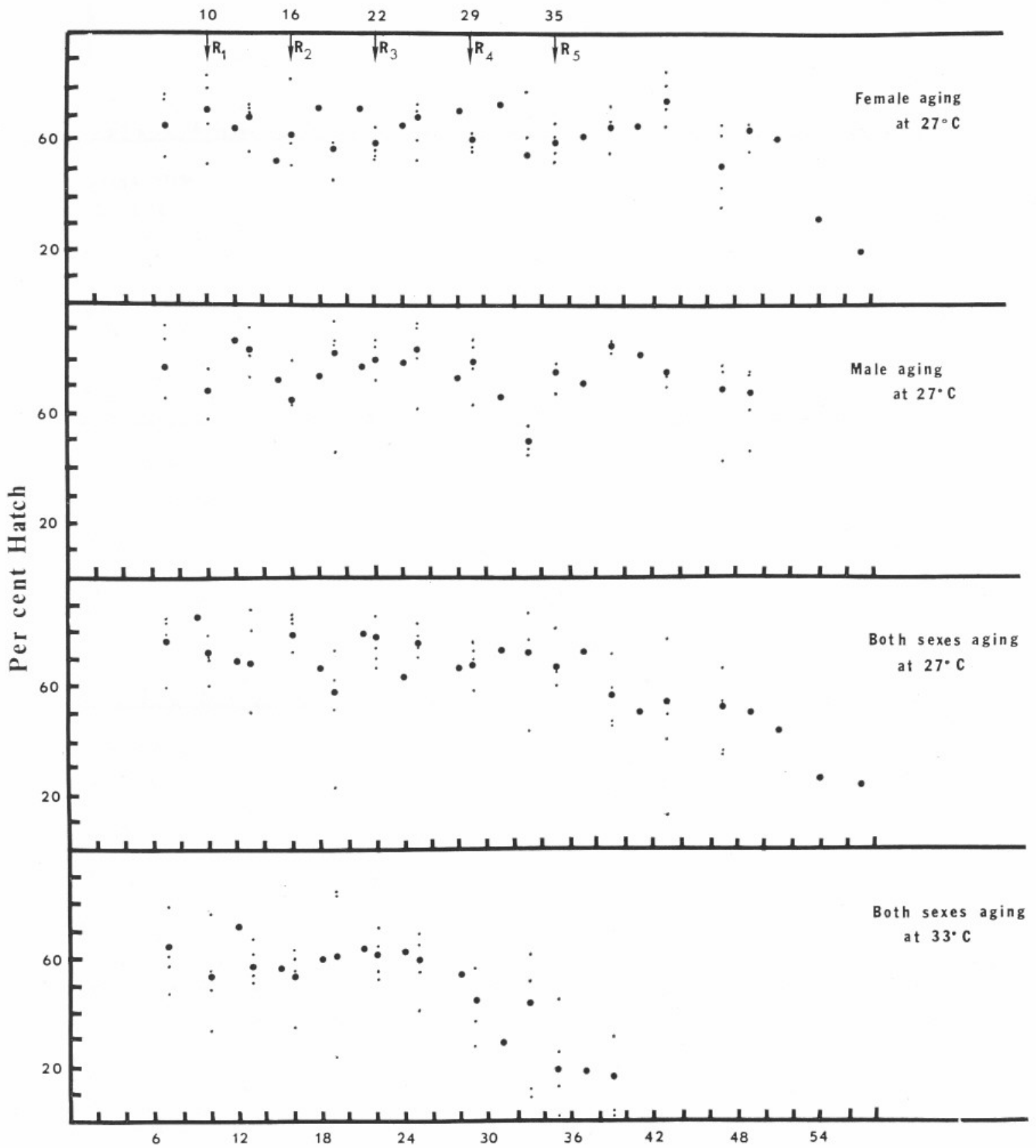

Age in Days

FIG. 1.- Hatchability of eggs of $H$. pusio as a function of maternal and paternal age.

Small dots represent individual replications; large dots their weighted mean The arrows $R_{1}$, $R_{2}$, etc., indicate the times in days (given on the top horizontal axis) of replacements of the nonaging sex by young individuals. 


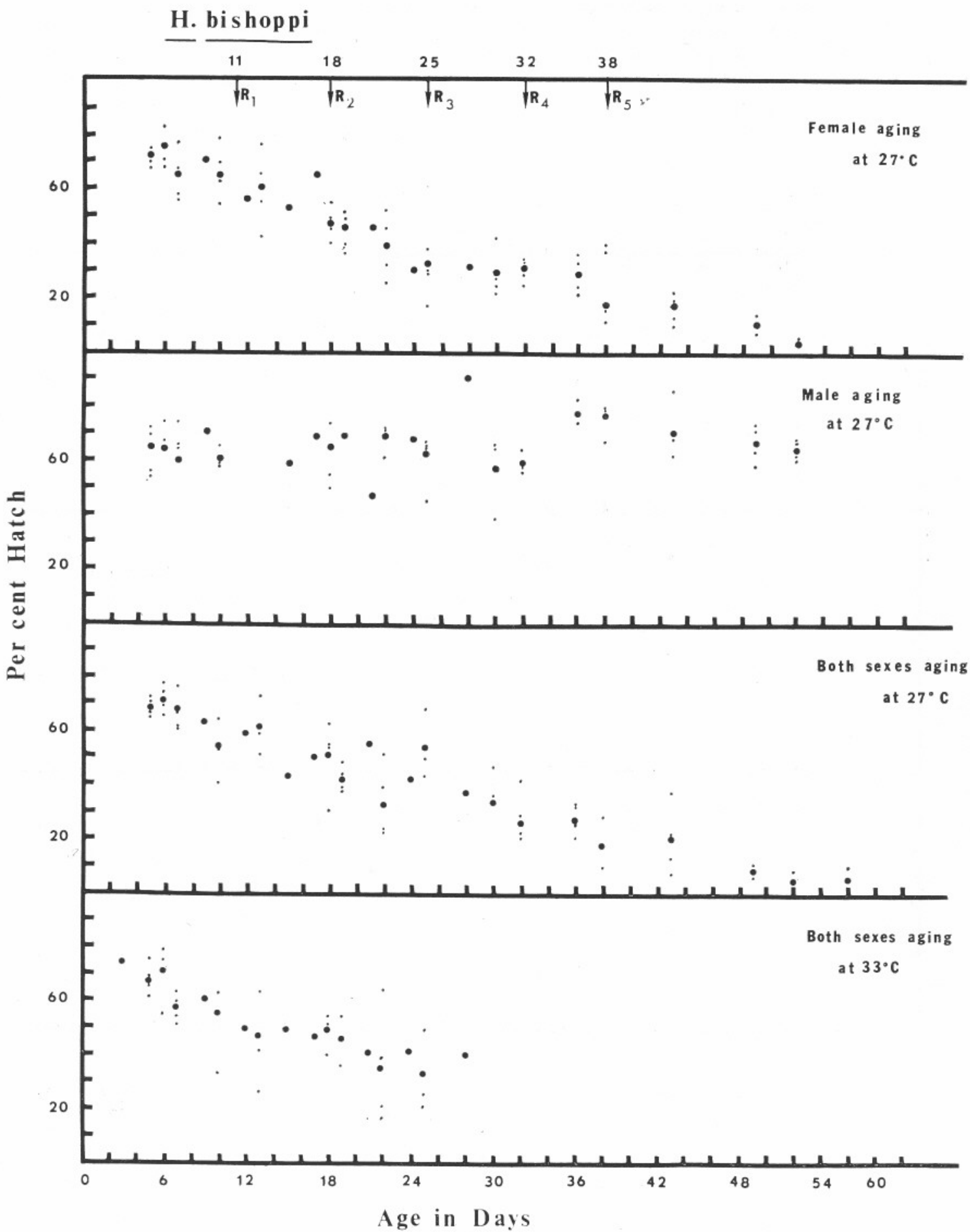

FIG. 2.- Hatchability of eggs of $H$. bishoppi as a function of maternal and paternal age.

Small dots represent individual replications; large dots their weighted mean The arrows $R_{1}$, $R_{2}$, etc., indicate the times in days (given on the top horizontal axis) of replacements of the nonaging sex by young individuals.

The solution of (1) is: $\mathrm{y}(\mathrm{t})=100 \mathrm{e}^{-\mathrm{kt}}$, and $\log \mathrm{y}(\mathrm{t})=2+\mathrm{bt}$ where $\mathrm{b}=-\mathrm{k} \log _{10} \mathrm{e}=-\mathrm{k}$ $(0.4343)$. If, the hypothesis expressed in (1) is correct, then a plot of $\log y(t)$ on $t$ should yield a straight line, as in Fig. 4. In Fig. 4, the data for each species were pooled. The regression lines given were computed with the restriction of the $y$ intercept to be 100 , i.e., the $z=\log y$ intercept to be 2 . 


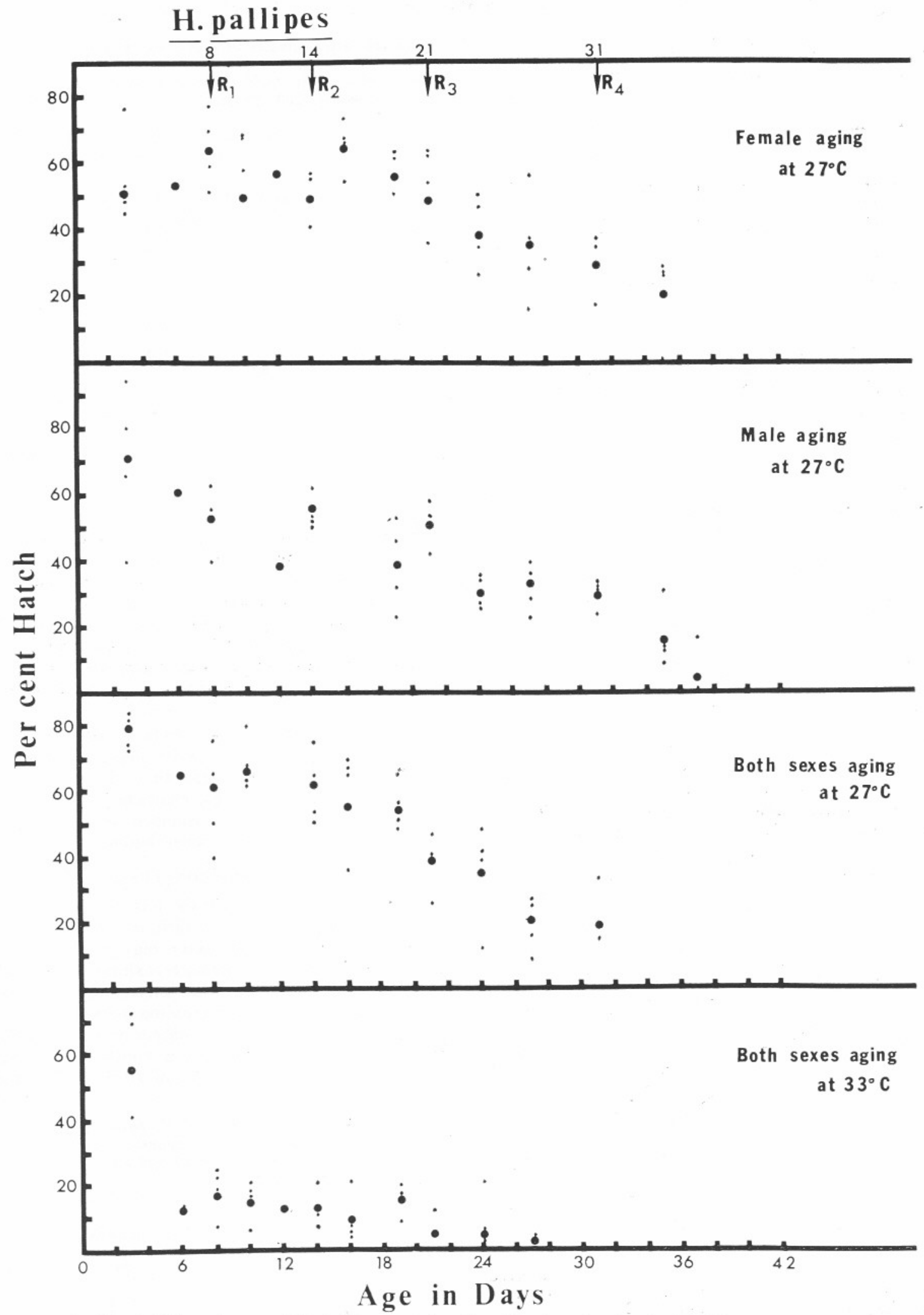

FIG. 3.- Hatchability of eggs of $H$. pallipes as a function of maternal and paternal age.

Small dots represent individual replications; large dots their weighted mean The arrows $R_{1}, R_{2}$, etc., indicate the times in days (given on the top horizontal axis) of replacements of the nonaging sex by young individuals. 
Table 1.-Hatchability $(\%)$ of eggs laid at successive time intervals after females of 3 species of Hippelates were deprived of males.

\begin{tabular}{|c|c|c|c|c|c|c|c|c|c|c|c|c|c|c|c|c|c|c|}
\hline \multirow[b]{2}{*}{ R group ${ }^{a}$} & \multicolumn{18}{|c|}{ Days after females were deprived of males } \\
\hline & 0 & 2 & 3 & 4 & 5 & 6 & 7 & 8 & 9 & 10 & 11 & 12 & 13 & 14 & 15 & 16 & 18 & 19 \\
\hline \multicolumn{19}{|c|}{ H. pusio } \\
\hline $\begin{array}{ll}1 & (10) \\
3 & (22) \\
4 & (29) \\
5 & (35)\end{array}$ & $\begin{array}{l}68.5 \\
79.7 \\
78.6 \\
74.9\end{array}$ & $\begin{array}{l}60.6 \\
80.9 \\
74.6 \\
69.3\end{array}$ & $\begin{array}{l}48.0 \\
65.5\end{array}$ & $\begin{array}{l}55.0 \\
55.4\end{array}$ & 40.4 & $\begin{array}{l}46.3 \\
40.1 \\
43.4 \\
32.9\end{array}$ & 7.5 & $\begin{array}{l}40.1 \\
22.1 \\
12.0\end{array}$ & $\begin{array}{r}19.0 \\
4.5\end{array}$ & 7.7 & $\begin{array}{r}16.9 \\
0.0\end{array}$ & $\begin{array}{l}6.6 \\
3.1 \\
1.8\end{array}$ & 0.0 & $\begin{array}{l}3.8 \\
1.1 \\
1.1\end{array}$ & $\begin{array}{l}5.2 \\
0.7\end{array}$ & 0.8 & $\begin{array}{l}1.2 \\
0.5\end{array}$ & 0.5 \\
\hline \multicolumn{19}{|c|}{ H. bishoppi } \\
\hline $\begin{array}{ll}1 & (11) \\
3 & (25) \\
5 & (38)\end{array}$ & $\begin{array}{l}60.1 \\
61.7 \\
76.8\end{array}$ & 67.6 & $\begin{array}{l}29.2 \\
35.2\end{array}$ & & $\begin{array}{l}32.0 \\
12.1 \\
29.0\end{array}$ & & $\begin{array}{r}13.8 \\
6.1\end{array}$ & 4.9 & 1.0 & & $\begin{array}{r}.0 \\
3.2\end{array}$ & & & 0.0 & & & 1.6 & \\
\hline \multicolumn{19}{|c|}{ H. pallipes } \\
\hline $\begin{array}{ll}1 & (1) \\
3 & (21) \\
4 & (31)\end{array}$ & $\begin{array}{l}52.3 \\
55.5 \\
50.8 \\
29.9\end{array}$ & 37.6 & 31.8 & 9.4 & $\begin{array}{l}25.0 \\
15.5\end{array}$ & 20.5 & 9.9 & 12.9 & & $\begin{array}{l}0.8 \\
2.8\end{array}$ & 6.8 & & .2 & 1.3 & & .0 & & \\
\hline
\end{tabular}

a Replacement groups shown in Fig. 1, 2, and 3. Numerals in parentheses are the ages (in days) of males at the time of female removal.

Under this restriction, the estimator for the slope $\mathrm{b}$ was derived and found to be

$$
\mathrm{b}=\frac{\Sigma \mathrm{tz}-2 \Sigma \mathrm{t}}{\Sigma \mathrm{t}^{2}} \text {. }
$$

The slopes of the regression lines for $H$. pusio, $H$. bishoppi, and $H$. pallipes were $-0.177,-0.226$, and -0.222 , respectively. It can be read from the graph that $71 \%$ of $H$. pusio and $79 \%$ of $H$. bishoppi and $H$. pallipes sperm were utilized within 3 days following male deprivation. Considering that the mean time between gonotrophic cycles of $H$. pusio is 3.2 days, ${ }^{3}$ it can be concluded that $74 \%$ of the sperm stored in the spermathecae of $H$. pusio are utilized in the 1st gonotrophic cycle following male deprivation. Therefore, these species require at least one mating per gonotrophic cycle to maintain enough sperm to fertilize all their viable eggs.

An additional experiment was conducted with only

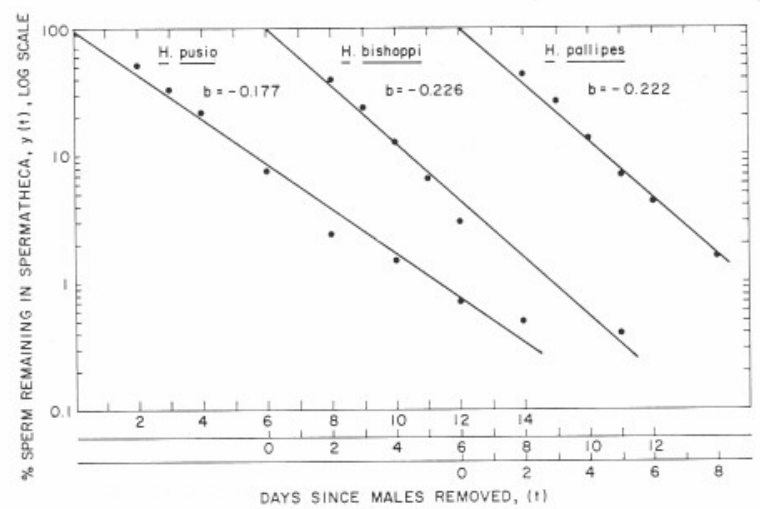

FIG. 4.-Utilization of sperm stored in the spermathecae of female $H$. pusio, $H$. bishoppi, and $H$. pallipes following male deprivation, expressed as percent of the total amount of sperm utilized during the entire life span. Regression lines were computed with a restriction for the $\mathrm{y}$ intercept.
$H$. pusio. The females whose percent of fertile eggs diminished to zero after male deprivation were again confined with young males and the hatchability of their eggs was observed. The females were capable of producing hatchable eggs again upon their reassociation with males, even after a prolonged (33 days) period of isolation (Table 2). However, the hatchability was lower than that of females of the same age which were never deprived of males.

During the course of this study it was observed that older females of all 3 species deposited proportionately more abnormal eggs than did young females. Those abnormal eggs, characterized by small size. distorted shape with rounded ends, and irregular follicular patterns, never hatched.

\section{DISCUSSION AND CONCLUSIONS}

The age-related changes in the fertility of 3 closely related species of Hippelates differed. Each sex of $H$. pusio maintained a constant high fertility until the end of its life. H. bishoppi exhibited a linear decline in egg viability with increasing maternal age, but no change with increasing paternal age.

When young males of $H$. pallipes were available, the females produced eggs of a constant hatching rate $(60 \%)$ up to about the age of 19 days, then the

Table 2.-Hatchability (\%) of $H$. pusio eggs laid by females of various ages kept continuously with males and by females deprived of males for 21 and 33 days and then confined with young males,

\begin{tabular}{cccccccc}
\hline \hline \multirow{2}{*}{$\begin{array}{c}\text { Days } \\
\text { deprived } \\
\text { of } \\
\text { males }\end{array}$} & 34 & 36 & 39 & 42 & 49 & 51 & 54 \\
\cline { 2 - 8 }$y$ & \multicolumn{6}{c}{ Age of females in days } \\
\hline 0 & 63.3 & 65.0 & 60.8 & 61.3 & 56.4 & 51.8 & \\
21 & 47.5 & 50.0 & 40.2 & 29.9 & & & \\
33 & & & & & 33.2 & 36.9 & 25.2 \\
\hline
\end{tabular}


rate declined. The same situation existed when both sexes aged. When only the males aged, egg fertility declined more uniformly during the entire time period which suggests that the rate of sperm production and/or transfer to the female system declines with the age of males. Thus, the rate of sperm production and/or transfer by those older males is sufficient to fertilize a high proportion of eggs of old females, which have a low fecundity rate, but it is not sufficient to fertilize a high proportion of eggs produced by young females, which have a high fecundity rate.

The data on $H$. pusio are similar to those obtained with beetles by Reynolds (1944), using Tribolium destructor Uyttenboogaart, and Segrove (1951), using Sitophilus (as Calandra) oryzae (L.) In those species, fertility remained virtually constant throughout life. In the case of the fly, Dacus oleae (Gmelin), the hatchability of eggs of young females mated with males of various ages remained constant up to 36th day of paternal age (Tsiropoulos and Tzanakakis 1970).

In many insect species, maternal age is an important factor determining viability of eggs. Parsons (1962) found that the viability of the eggs of $D$. melanogaster increased for a short period at the beginning of oviposition then decreased with the age of parents. Robertson and Sang (1944) obtained the same results with $D$. melanogaster and also found that the male had a negligible effect and that the changes in egg viability were associated with the physiological changes of the female as she aged. Maternal age is the important factor in egg viability in H. bishoppi.

The hatching rate of Anopheles quandrimaculatus Say eggs decreased in successive lots (Love 1954). According to Love, the reduction in the rate of hatching is probably a result of the production of nonviable ova. He suggested that sufficient sperm could be retained by the female, if associated with males for 4 days, to fertilize all the ova produced during her lifetime. This situation is apparently not the case with Hippelates. Eggs from females of $H$. pusio that were maintained in association with males up to ca. 50 days showed a constant rate of hatchability. When females were deprived of males hatchability dropped to practically zero within 15 days. For this species, therefore, the regression slope $(\mathrm{b}=$ $-0.177)$ in Fig. 4 reflects either the reduction in the amount of sperm remaining in the spermathecae or the reduction in the amount and viability of the sperm. The reduction in hatchability of $H$. bishoppi and $H$. pallipes eggs (Table 1 ) is also too great to be exclusively a result of the aging of the females (Fig. 2, 3). However, the greater regression slopes ( $b=-0.226$ and $b=-0.222$ ) (Fig. 4) for these 2 species, compared to the slope for $H$. pusio, indicate that the reduction in hatchability of $H$. bishoppi and $H$. pallipes eggs is partially a result of the production of an increasing proportion of nonviable ova with maternal age, which agrees with the data in Fig. 2 and 3.
$H$. pallipes has a very low tolerance to higher temperatures with respect to various biological functions, as compared with the other 2 species (Karandinos and Axtell 1967a, b). The sterilizing effects of high temperature on this species are consistent with those previous findings.

At $33^{\circ} \mathrm{C}$, the fertility of $H$. pusio adults was significantly lower than at $27^{\circ} \mathrm{C}$ (Fig. 1). The test was based on hatching records for days $7,10,13$, 16,19 , and 22 , i.e., before the flies began to die. On the other hand, the data show that in all treatments, including the one at $33^{\circ} \mathrm{C}$, hatchability did not exhibit any declining trend with age until the population reached its dying phase, the onset of which depended on temperature. Therefore, the higher temperature did not accelerate the rate of aging of $H$. pusio, although it reduced the level of fertility apparently by means of direct effects on gametes and/or mating frequency.

At $33^{\circ} \mathrm{C}$, hatchability of $H$. bishoppi eggs declined with age slightly faster than at $27^{\circ} \mathrm{C}$. The hatchability of eggs obtained at $33^{\circ} \mathrm{C}$ from young parents (day 5, 6, and 7) was not significantly different $(5 \%$ level $)$ from those at $27^{\circ} \mathrm{C}$. We concluded that $33^{\circ} \mathrm{C}$ did not directly affect the reproduction of $H$. bishoppi, but it accelerated the rate of aging as manifested by the hatchability of eggs.

The age-specific fertility of an insect species is of importance for 2 reasons. First, the development of a realistic model of insect population dynamics requires data on age-specific fertilities. Second, analysis of data of this kind may lead to plausible hypotheses concerning the nature of underlying physiological and/or structural changes in the insect's reproductive system with the passage of time.

\section{REFERENCES CITED}

Beament, J. W. L. 1947. The formation and structure of the micropylar complex in the egg-shell of Rhodnius prolixus Stäh1. (Heteroptera Reduviidue). J. Exp. Biol. 23: 213-33.

Grosch, D. S. 1968. Reproductive performance of female braconids compared after (A) brief and (B) protracted exposure to ionizing radiations, p. 37789. In Isotopes and Radiation in Entomology. Int. At. Energy Agency Proc. Ser. Vienna, STI/PUB/ 166. $428 \mathrm{p}$.

Johansson, A. S. 1958. Relation of nutrition to endocrine reproductive functions in the milkweed bug Oncopeltus fasciatus (Dallas) (Heteroptera: Lygaeidae). Nytt Mag. Zool. 7:1-132.

Karandinos, M. G., and R. C. Axtell. 1967a. Temperature effects on the immature stages of Hippelates pusio, H. bishoppi, and $H$. pallipes (Diptera: Chloropidae). Ann. Entomol. Soc. Am. 60: 1055-62.

$1967 \mathrm{~b}$. Effect of temperature on the longevity, fecundity, and activity of adult Hippelates pusio, $H$. bishoppi, and $H$. pallipes (Diptera: Chloropidae). Ibid. 60 : 1252-5.

1972. Population density effects on fecundity of fecundity of Hippelates pusio Loew (Diptera: Chloropidae). Oecologia. (In press.)

Love, G. J. 1954. Variations on hatching of ova in successive lots obtained from colonized Anopheles quadrimaculatus Say. J. Econ. Entomol. 47: 178-9.

Ludwig, D., and C. Fiore. 1960. Further studies on the relationship between parental age and the life cycle of 
the mealworm, Tenebrio molitor. Ann. Entomol. Soc. Am. 53: 595-600.

McMillan, I., M. Fitz-Earle, and D. S. Robson. 1970a. Quantitative genetics of fertility. I. Lifetime egg production of Drosophila melanogaster-Theoretical. Genetics $65(2)$ : 349-53.

1970b. Quantitative genetics of fertility. II. Lifetime egg production of Drosophila melanogaster-Experimental. Ibid. 65(2) : 355-69.

Parsons, P. A. 1962. Maternal age and development variability. J. Exp. Biol. 39: 251-60.

Raros, R. S., and H. C. Chiang. 1969. Maternal age as an ecological factor in the population dynamics of the European corn borer Ostrinia mubilalis. Entomol. Exp. Appl. 12: 74-80.

Reynolds, J. M. 1944. The biology of Tribolium destructor Uytt. 1. Some effects of fertilization and food factors on fecundity and fertility. Ann. Appl. Biol. 31: 132-42.

Robertson, F. W., and J. H. Sang. 1944. The ecological determinants of population growth in a Drosophila culture. II. Circumstances affecting egg viability. Proc. R. Entomol. Soc. Lond. 132: 277-91.

Segrove, F. 1951. Oviposition behavior in the two strains of the rice weevil, Calandra orvzae Linn. (Coleopt., Curculionidae). J. Exp. Biol. 28: 281-97.

Shapiro, H. 1932. The rate of oviposition in the fruit fly, Drosophila. Biol. Bull. (Woods Hole) 63(3): 456-71.

Smith, D. S. 1964. Ovarioles and developing eggs in grasshoppers. Can. Entomol. 96: 1255-8.

Strehler, B. L. 1962. Time, Cells, and Aging. Academic Press, New York. 270 p.

Tsiropoulos, G. J., and M. E. Tzanakakis. 1970. Mating frequency and inseminating capacity of radiationsterilized and normal males of olive fruit fly. Ann. Entomol. Soc. Am. 63: 1007-10.

Wattiaux, J. M. 1967. Influence de l'âge sur le fonctionnement ovarien chez Drosophila melanogaster. J. Insect Physiol. 13 : 1279-82.

Reprinted from the

Annals of the Entomological Society of America 